\title{
Wheat Gluten-Laminated Paperboard with Improved Moisture Barrier Properties: A New Concept Using a Plasticizer (Glycerol) Containing a Hydrophobic Component (Oleic Acid)
}

\author{
Sung-Woo Cho, ${ }^{1}$ Thomas O. J. Blomfeldt, ${ }^{1}$ Helena Halonen, ${ }^{2}$ \\ Mikael Gällstedt, ${ }^{2}$ and Mikael S. Hedenqvist ${ }^{1}$ \\ ${ }^{1}$ Department of Fibre and Polymer Technology, KTH Royal Institute of Technology, 10044 Stockholm, Sweden \\ ${ }^{2}$ Innventia, P.O. Box 5604, 11486 Stockholm, Sweden \\ Correspondence should be addressed to Mikael S. Hedenqvist, mikaelhe@kth.se
}

Received 15 October 2011; Revised 27 March 2012; Accepted 30 March 2012

Academic Editor: Wen Fu Lee

Copyright () 2012 Sung-Woo Cho et al. This is an open access article distributed under the Creative Commons Attribution License, which permits unrestricted use, distribution, and reproduction in any medium, provided the original work is properly cited.

\begin{abstract}
This paper presents a novel approach to reduce the water vapor transmission rate (WVTR) and water absorbance of wheat gluten/paperboard laminates by introducing a hydrophobic component (oleic acid (OA)) into the hydrophilic plasticizer (glycerol). Whereas the paperboard showed immeasurably high WVTR, the laminate with gluten/glycerol yielded finite values. More importantly, by incorporating $75 \mathrm{wt} . \%$ OA into the plasticizer, the WVTR and water absorbance were reduced by, respectively, a factor of three and 1.5-2. Of particular interest was that the mechanical properties were not changing dramatically between 0 and $50 \mathrm{wt} . \%$ OA. The results showed clear benefits of combining a gluten film with paperboard. Whereas the paperboard provided toughness, the WG layer contributed with improved moisture barrier properties. In addition, WVTR indicated that the paperboard reduced the swelling of the outer gluten/glycerol layer in moist conditions; a free standing gluten/glycerol film would yield infinite, rather than finite, WVTR values.
\end{abstract}

\section{Introduction}

Wheat gluten (WG) is an interesting alternative to petroleum-based polymeric materials [1] and is available in large quantities as a byproduct from the wheat starch industry [2]. WG films are, however, brittle, and a plasticizer is therefore needed. Using, for example, glycerol, it is possible to make WG-based films and $3 \mathrm{D}$ objects using conventional polymer-processing techniques including compression molding, extrusion, and injection molding [3-6]. The resulting material has good gas barrier properties under dry conditions [7], and in its plasticized state it resembles PVC with a high content of plasticizer.

Paperboard coatings for food packaging applications are commonly made from petroleum-based polymers. These coatings are essential for the lifetime of the food products as they act as oxygen and/or water/water vapor barriers [8]. Since wheat gluten is able to form films [1] and has a low oxygen permeability (OP) under dry conditions [9], it is interesting as an alternative in environment-friendly edible and nonedible films for paperboards in food packaging [8]. However, the fact that wheat gluten is hydrophilic and has a high water permeability limits its uses; an effective control of moisture transfer is essential for most foods [10].

Previous studies have shown that the water vapor permeability (WVP) can be reduced when a lipid, such as oleic acid (OA), is incorporated into edible films where the main component is whey [11], chitosan [10], and wheat gluten $[12,13]$. However, lipids tend to negatively influence the mechanical properties. In [11] the oleic acid was added after the protein/glycerol emulsion had been prepared and in [10] it was mixed directly with the polymer. In [12] the lipids were coated onto the WG matrix, and in [13] cast films were made from WG, glycerol, and lipids in water and ethanol.

In the work presented in this paper, a new concept of incorporating a lipid, oleic acid, into a wheat gluten material 


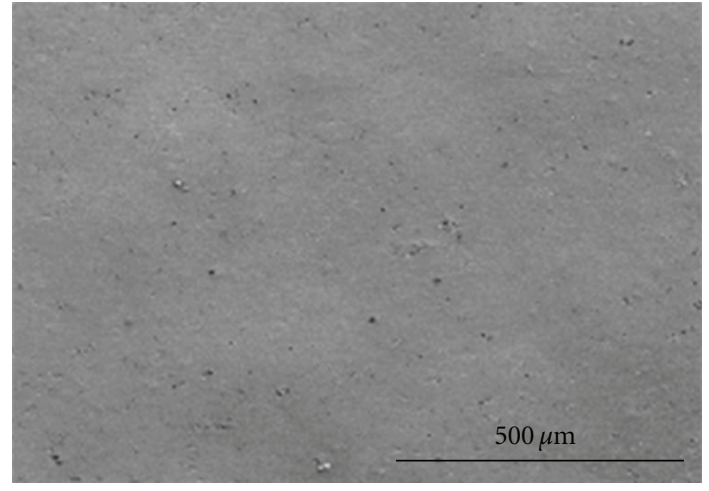

(a)

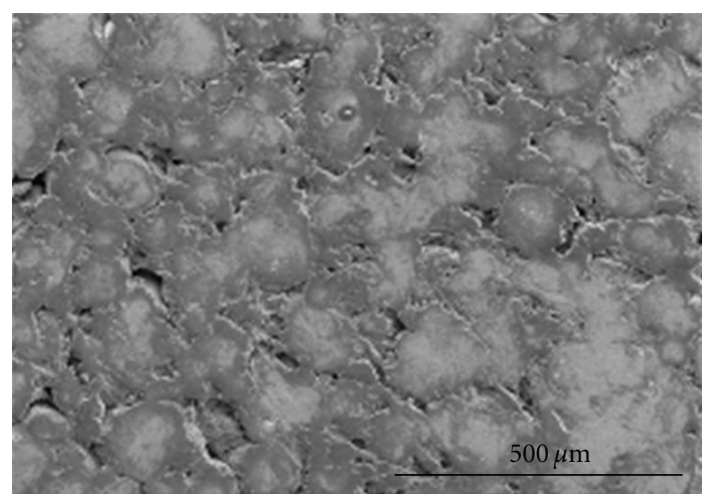

(c)

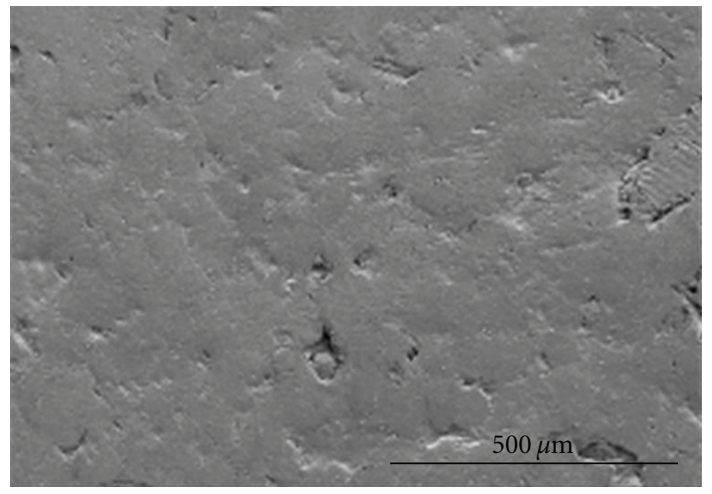

(b)

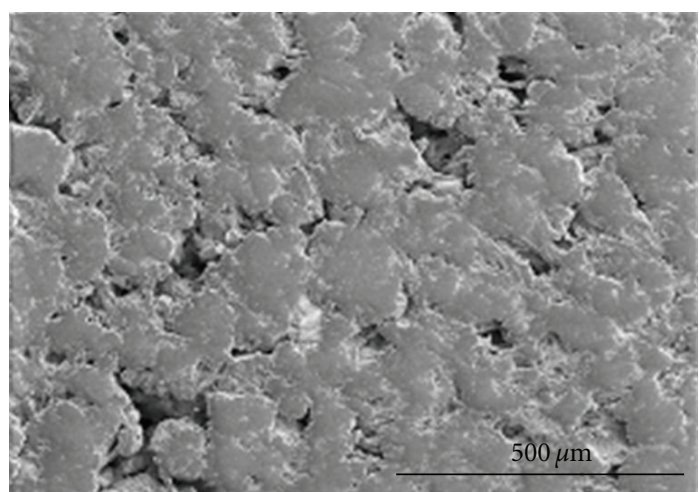

(d)

FIGURE 1: SEM images showing the surfaces of the WG layer with $20 \mathrm{wt} . \%$ of plasticizer containing glycerol and oleic acid in the mass proportions: (a) $100: 0$, (b) $75: 25$, (c) $50: 50$, and (d) $25: 75$.

intended for thermoforming was investigated in order to achieve a more water-resistant material and a higher water vapor barrier without any loss in mechanical properties. The concept was applied to wheat gluten-coated paperboard. The more hydrophobic component (oleic acid) was mixed with the plasticizer (glycerol) prior to adding these to the WG. The oleic acid/glycerol/WG mixture was subsequently applied to the paperboard by compression-molding to mimic extrusion-coating/lamination.

A possible future packaging material for dry foods is a $100 \%$ renewable wheat gluten laminate on the outside of the paperboard where the outer layer (consisting of WG with oleic acid/glycerol) is a sufficient water vapor barrier to protect the inner oxygen barrier layer (WG with a small amount of glycerol [14]).

\section{Materials and Methods}

2.1. Materials. Commercial WG powder was kindly supplied by Reppe AB, Lidköping, Sweden. According to the supplier, the gluten protein content was $77.7 \%$ (according to a modified NMKL nr6 method, Kjeltec, Nx5.7; http://www.nmkl .com/). Glycerol with a concentration of $\geq 99.5 \mathrm{wt} . \%$ and a moisture content of $\leq 0.5 \mathrm{wt}$. $\%$ was supplied by Karlshamns Tefac AB, Karlshamn, Sweden. Oleic acid (OA, $\left.\mathrm{C}_{18: 1}\right)$ was purchased from Sigma-Aldrich Co., St. Louis, MO, USA. The paperboard, Korsnäs Duplex 260, was provided by Korsnäs AB, Gävle, Sweden. The grammage was $242 \mathrm{~g} / \mathrm{m}^{2}$ and the thickness was $0.4 \mathrm{~mm}$. The bottom layer of the paperboard, which was used as a substrate for the lamination, consisted of unbleached softwood sulphite pulp. The middle layer consisted of unbleached chemi-thermomechanical pulp (CTMP), and the top layer consisted of a blend of bleached softwood and hardwood. The hydrophobization was obtained using a dual sizing agent with alkyl ketene dimer (AKD) and rosin. The paperboard was not surface coated on the bottom side.

2.2. Sample Preparation. The WG-coated paperboards were prepared by compression molding using a Table-Top Press, Polystat 200T (Servitec Maschinenservice GmbH, Wustermark, Germany). A homogeneous dough was first prepared by mixing WG powder with plasticizer (glycerol with or without oleic acid) in a mortar. For simplicity, in the remainder of the study, the glycerol/oleic acid mixture is referred to as the plasticizer. The plasticizer content was 20 or $30 \mathrm{wt} . \%$, based on the total mass of WG films, and the relative contents (wt.\%) of oleic acid and glycerol were $0: 100,25: 75,50: 50$, and $75: 25$. Ten grams of the dough was spread evenly inside a frame $\left(14 \times 14 \mathrm{~mm}^{2}\right)$ between 


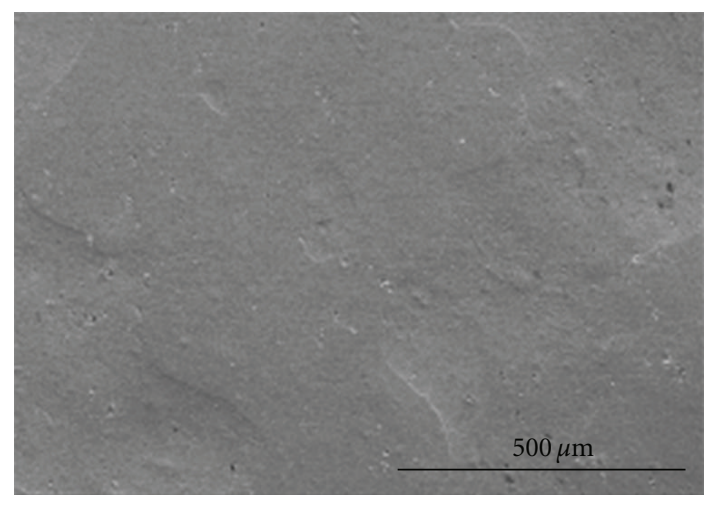

(a)

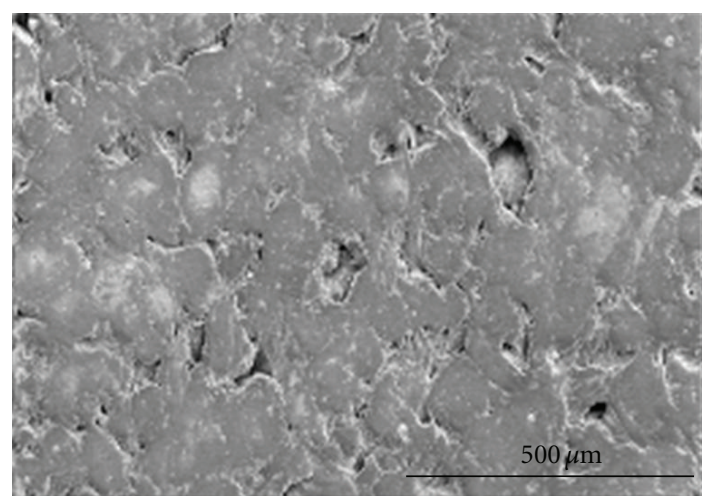

(c)

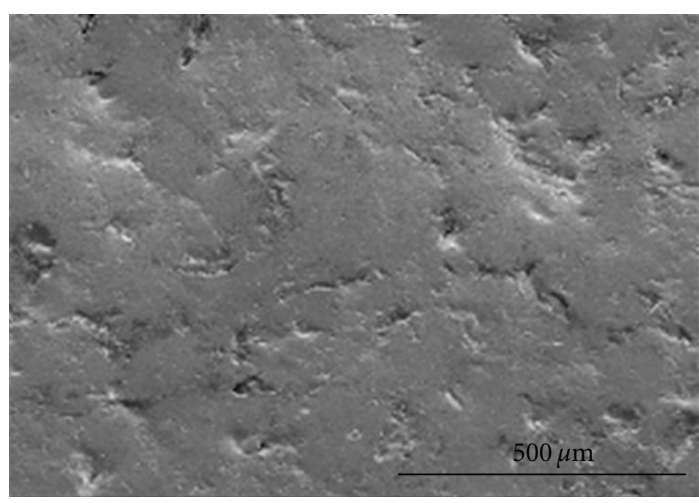

(b)

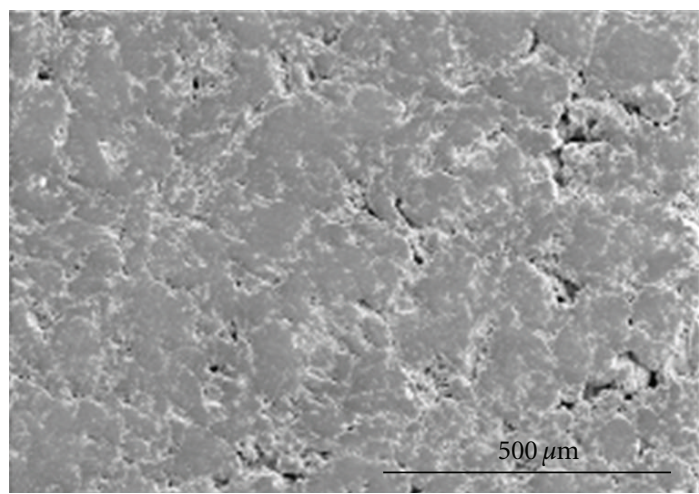

(d)

FIGURE 2: SEM images showing the surfaces of the WG layer with $30 \mathrm{wt} \%$ of plasticizer containing glycerol and oleic acid in the mass proportions: (a) $100: 0$, (b) $75: 25$, (c) $50: 50$, and (d) $25: 75$.

TABLE 1: Water vapor transmission rate and surface water absorption.

\begin{tabular}{|c|c|c|c|c|c|}
\hline \multirow{2}{*}{$\begin{array}{l}\text { Plasticizer } \\
\text { content (wt.\%) }\end{array}$} & \multicolumn{5}{|c|}{ Specific water vapor transmission rate $\left(\mathrm{g} \cdot \mathrm{mm} /\left(\mathrm{m}^{2} \cdot\right.\right.$ day $\left.)\right)$} \\
\hline & Paperboard & 0 wt. $\%$ OA & 25 wt. $\%$ OA & 50 wt. $\%$ OA & 75 wt. $\%$ OA \\
\hline 20 & $\mathrm{UH}^{*}$ & $400 \pm 41 \mathrm{ab}$ & $260 \pm 5 \mathrm{de}$ & $199 \pm 11 \mathrm{def}$ & $123 \pm 6 \mathrm{f}$ \\
\hline \multirow[t]{2}{*}{30} & & $477 \pm 41 \mathrm{a}$ & $370 \pm 16 b c$ & $275 \pm 44 \mathrm{~cd}$ & $164 \pm 8$ ef \\
\hline & \multicolumn{5}{|c|}{$\mathrm{Cobb}_{60}$ water absorbency $\left(\mathrm{g} / \mathrm{m}^{2}\right)$} \\
\hline 20 & $24.3 \pm 0.3 \mathrm{e}^{* *}$ & $42.5 \pm 1.1 \mathrm{~b}$ & $32.1 \pm 0.5 c$ & $28.0 \pm 0.4 \mathrm{~d}$ & $28.4 \pm 0.7 \mathrm{~d}$ \\
\hline 30 & & $48.4 \pm 1.0 \mathrm{a}$ & $33.6 \pm 1.2 \mathrm{c}$ & $28.9 \pm 0.6 \mathrm{~d}$ & $24.3 \pm 0.1 \mathrm{e}$ \\
\hline
\end{tabular}

The results are given with the average value, standard deviation, and significance letter.

*UH: immeasurably high.

** The values having the same letters are not significantly different. Statistics were carried out using the Tukey-Kramer HSD test at a significance level of 0.05 .

two Mylar films and two metal plates. The compression molding was performed at $110^{\circ} \mathrm{C}$ for $30 \mathrm{~s}$, and the molding pressure was set to 200 bar on the machine gauge. The plate assembly was removed from the press after the pressure had been released, and the WG films were separated from the frame using a scalpel. The paperboards were subsequently coated with the prepared films using the same procedure, but without the frame. The WG films were placed on the bottom side of the paperboard, and the molding was carried out at $110^{\circ} \mathrm{C}$ under a set pressure of 200 bar for $10 \mathrm{~min}$. The WG-laminated paperboards were taken from the press and stored at $23^{\circ} \mathrm{C}$ and $50 \% \mathrm{RH}$ prior to characterization and measurements.

2.3. Water Vapor Transmission Rate Measurements. The water vapor transmission rate was measured using a Mocon Permatran-W $3 / 31$ at $38^{\circ} \mathrm{C}$ and $90 \% \mathrm{RH}$ (MOCON Inc., Minneapolis, MN, USA) according to ASTM F 1249-90. The specimens (two replicates of each sample) were tightly sandwiched between two aluminum foils, providing a $5 \mathrm{~cm}^{2}$ exposure area. The steady-state flow rate through the specimen was then determined and normalized with respect to 


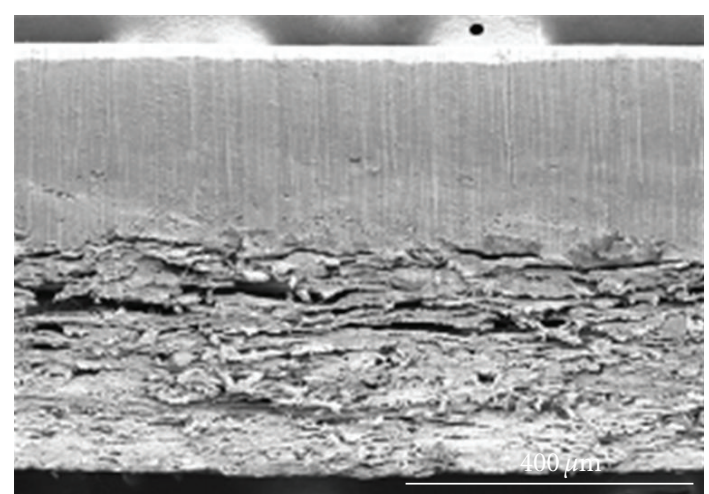

(a)

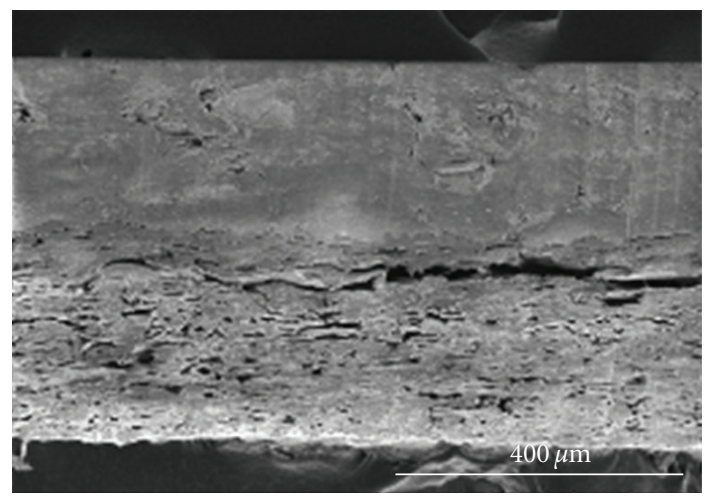

(c)

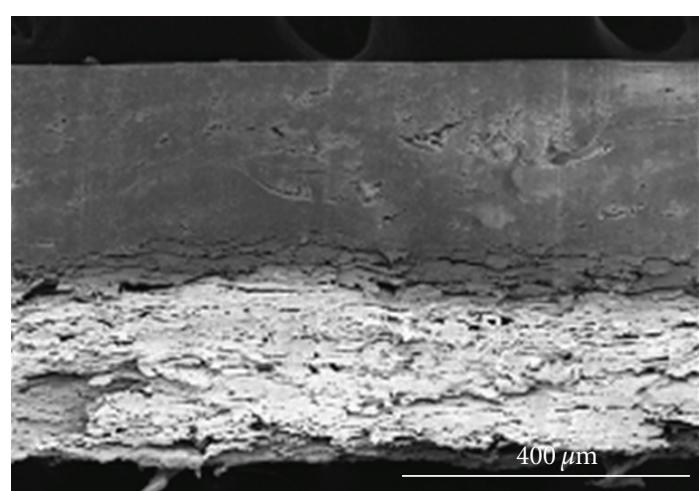

(b)

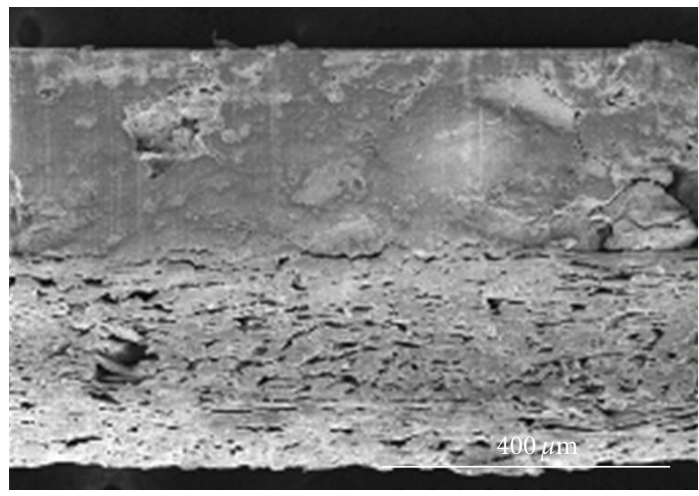

(d)

Figure 3: Cross-sections of the samples containing 20 wt.\% plasticizer with (a) 0 wt.\%, (b) 25 wt.\%, (c) 50 wt.\%, and (d) 75 wt.\% OA. The top denser part is the gluten layer, and the bottom porous part is the paperboard.

TABLE 2: Mechanical properties of the uncoated and laminated paperboard.

\begin{tabular}{|c|c|c|c|c|c|}
\hline Sample & E-modulus (GPa) & Strain at break $(\%)$ & Stress at break $(\mathrm{MPa})$ & Energy at break $\left(\mathrm{mJ} / \mathrm{mm}^{2}\right)$ & Thickness (mm) \\
\hline Paperboard & $2.50 \pm 0.10 \mathrm{de}^{*}$ & $4.1 \pm 0.4 \mathrm{a}$ & $26.5 \pm 1.8 \mathrm{bc}$ & $30.6 \pm 4.0 \mathrm{a}$ & $0.40 \pm 0.01$ \\
\hline $20-\mathrm{OA} 0$ & $3.24 \pm 0.15 c$ & $1.5 \pm 0.1 \mathrm{~d}$ & $25.2 \pm 2.6 c$ & $9.5 \pm 1.4 \mathrm{~cd}$ & $0.59 \pm 0.02$ \\
\hline 20-OA25 & $3.64 \pm 0.16 b$ & $1.5 \pm 0.1 \mathrm{~d}$ & $29.2 \pm 2.6 \mathrm{ab}$ & $10.6 \pm 1.5 \mathrm{~cd}$ & $0.55 \pm 0.01$ \\
\hline 20-OA50 & $4.00 \pm 0.19 \mathrm{a}$ & $1.4 \pm 0.1 \mathrm{~d}$ & $32.3 \pm 2.4 \mathrm{a}$ & $11.1 \pm 1.6 \mathrm{~cd}$ & $0.54 \pm 0.03$ \\
\hline 20-OA75 & $2.61 \pm 0.09 \mathrm{~d}$ & $2.9 \pm 0.3 c$ & $9.1 \pm 1.5 \mathrm{f}$ & $11.9 \pm 1.8 \mathrm{c}$ & $0.63 \pm 0.02$ \\
\hline $30-\mathrm{OA} 0$ & $3.11 \pm 0.12 c$ & $1.4 \pm 0.1 \mathrm{~d}$ & $21.8 \pm 1.8 \mathrm{~d}$ & $7.7 \pm 1.2 \mathrm{~d}$ & $0.57 \pm 0.01$ \\
\hline 30-OA25 & $3.51 \pm 0.19 b$ & $1.4 \pm 0.1 \mathrm{~d}$ & $26.0 \pm 2.6 c$ & $8.8 \pm 1.0 \mathrm{~cd}$ & $0.51 \pm 0.02$ \\
\hline 30-OA50 & $3.94 \pm 0.23 \mathrm{a}$ & $1.3 \pm 0.1 \mathrm{~d}$ & $27.2 \pm 2.7 b c$ & $7.1 \pm 2.8 \mathrm{~d}$ & $0.49 \pm 0.01$ \\
\hline 30-OA75 & $2.32 \pm 0.06 \mathrm{e}$ & $3.7 \pm 0.4 \mathrm{~b}$ & $18.0 \pm 1.5 \mathrm{e}$ & $20.8 \pm 3.9 b$ & $0.50 \pm 0.01$ \\
\hline
\end{tabular}

Sample notation: wt.\% plasticizer-OA (wt.\% oleic acid in the plasticizer mixture).

*The values connected with the same letters are not significantly different. Statistics was carried out using the Tukey-Kramer HSD test at a significance level of 0.05 .

the thickness of the coated paperboards to yield the specific water vapor transmission rate $(s W V T R)$.

2.4. Water Absorbency by the Cobb 60 Method. The water absorption was determined by $\mathrm{Cobb}_{60}$ in accordance with SCAN-P 12:64. The measurements were performed using an L\&W Cobb Sizing Tester (Lorentzen \& Wettre, AB, Kista, Sweden) at $23 \pm 1{ }^{\circ} \mathrm{C}$ and $50 \pm 2 \% \mathrm{RH}$ in a controlled climate room. Samples were cut into dimensions of $13 \times 13 \mathrm{~cm}^{2}$ and conditioned in the climate-controlled room. The apparatus used consisted of a rubber-mat baseboard and a $5 \mathrm{~cm}$ high metal cylinder with an inner area of $100 \mathrm{~cm}^{2}$. The tester is provided with a clamping device to fasten the cylinder onto the baseboard, having the sample on top. $100 \mathrm{~mL}$ of distilled water was then poured into the cylinder. $C_{0} b b_{60}$ indicates that the absorption is measured after $60 \mathrm{~s}$. The water was poured out after $45 \mathrm{~s}$, the test piece was removed from 
TABLe 3: Gloss value and haze index of the laminated paperboard.

\begin{tabular}{|c|c|c|c|c|}
\hline \multirow{2}{*}{$\mathrm{Pc}^{*} / \mathrm{Ga}^{* *}$} & \multicolumn{4}{|c|}{ Gloss unit } \\
\hline & 0 wt. $\%$ OA & 25 wt. $\%$ OA & 50 wt. $\%$ OA & 75 wt. $\%$ OA \\
\hline $20 / G^{20}$ & $8.3 \pm 0.5$ & $5.3 \pm 0.4$ & $8.9 \pm 1.6$ & $14.4 \pm 1.9$ \\
\hline $20 / G^{60}$ & $44.6 \pm 1.8$ & $32.0 \pm 1.3$ & $35.3 \pm 2.2$ & $41.2 \pm 2.7$ \\
\hline 20/Haze index $* * *$ & $34.4 \pm 1.3$ & $26.6 \pm 0.9$ & $26.4+1.2$ & $26.8 \pm 1.9$ \\
\hline $30 / G^{20}$ & $7.2 \pm 2.0$ & $3.0 \pm 0.2$ & $8.0 \pm 3.8$ & $11.4 \pm 1.7$ \\
\hline $30 / G^{60}$ & $40.4 \pm 7.2$ & $21.2 \pm 1.2$ & $32.2 \pm 6.7$ & $39.0 \pm 2.6$ \\
\hline 30/Haze index & $33.2 \pm 5.2$ & $18.2 \pm 1.1$ & $24.2 \pm 3.4$ & $27.6 \pm 1.0$ \\
\hline
\end{tabular}

* The total plasticizer content in the coated paperboard (wt.\%).

$* * \mathrm{Gloss}^{\text {angle }(\circ)}$ : the reflectance measured at angles of $20^{\circ}$ and $60^{\circ}$.

$* * *$ Haze index defined as difference in gloss values measured at angles of $60^{\circ}$ and $20^{\circ}\left(H=G^{60}-G^{20}\right)$.

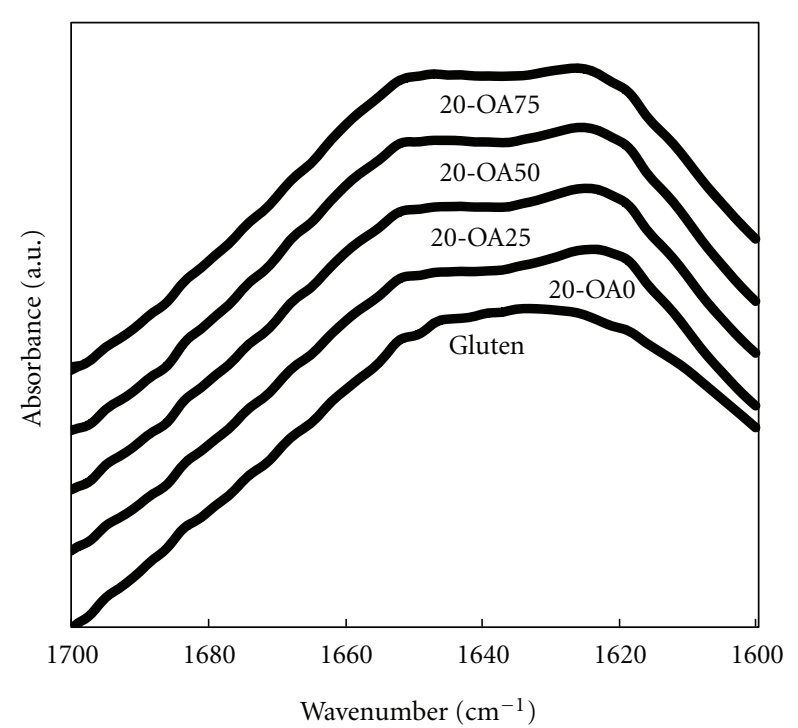

FIGURE 4: IR spectra for the samples containing $20 \mathrm{wt} . \%$ plasticizer in the amide I region. Sample notation: wt.\% plasticizer-OA (wt.\% oleic acid in the plasticizer mixture). For clarity the curves have been shifted vertically. Gluten refers to unprocessed wheat gluten.

the instrument after an additional $15 \mathrm{~s}$, and the residual water on the surface was removed by first laying a blotting paper on the sample and then rolling twice with a brass roller over it. After removal of the blotting paper, the film was weighed and the $\mathrm{Cobb}_{60}$ value, $X$ (water absorbency in $\mathrm{g} / \mathrm{m}^{2}$ ), was calculated as $X=100 \cdot\left(m_{f}-m_{i}\right)$, where $m_{f}$ and $m_{i}$ are the masses $(\mathrm{g})$ of the test piece after and before the water exposure [15]. Three replicates of each sample were tested.

\subsection{Field Emission Scanning Electron Microscopy (FE-SEM).} The WG layer surfaces, cross-sections, and tensile-fractured surfaces were examined in a Hitachi S-4800 FE-SEM (Hitachi High-Technologies Corporation, Tokyo, Japan). Before insertion in the microscope, the specimens were coated with gold to a thickness of ca. $6 \mathrm{~nm}$ using an agar high-resolution sputter coater (model 208RH) (Agar Scientific, Stansted, UK), equipped with a gold target/agar thickness monitor controller.

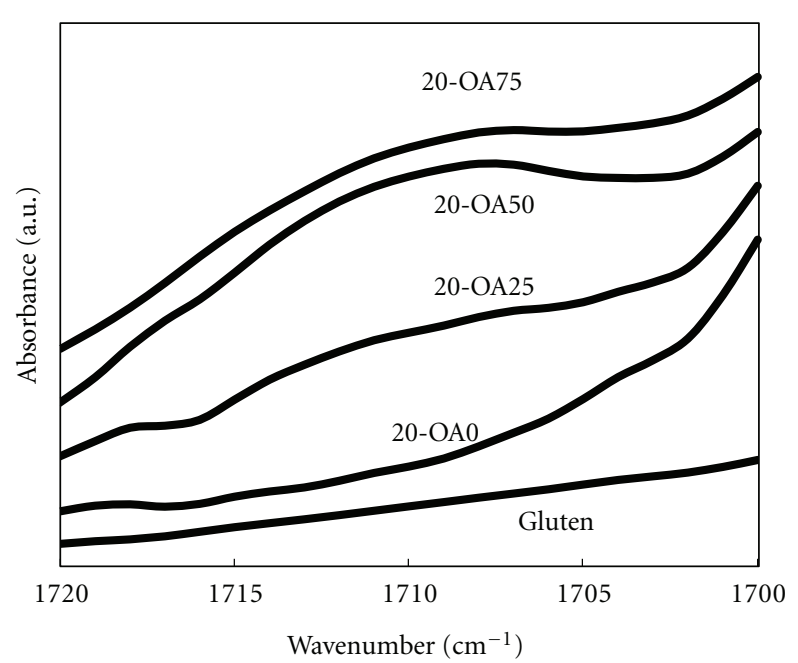

FIGURE 5: IR spectra for the samples containing $20 \mathrm{wt} \%$ plasticizer in the ester region. The notations are the same as in Figure 4. For clarity the curves have been shifted vertically. Gluten refers to unprocessed wheat gluten.

2.6. Infrared Spectroscopy (IR). Infrared spectra were recorded with a Perkin-Elmer Spectrum 2000 FTIR spectrometer, Perkin-Elmer Inc., Waltham, MA, USA, equipped with a single-reflection ATR accessory (Golden Gate from Specac Ltd., Orpington, UK) and controlled by the program Spectrum version 2.00, from Graseby Specac Ltd, Orpington, UK. The sample was tightly sandwiched between a sapphire anvil and the ATR germanium crystal with the WG-coated sample surface against the latter. The spectra were taken as an average of 16 scans between 4000 and $600 \mathrm{~cm}^{-1}$ at intervals of $1 \mathrm{~cm}^{-1}$ with a resolution of $4 \mathrm{~cm}^{-1}$.

2.7. Tensile Testing. The tensile tests were performed with an Instron 5566 Universal Testing machine (Instron, Norwood, MA, USA) according to ISO 527-3. Dumbbell-shaped specimens, having a width of $4 \mathrm{~mm}$ in the narrow section and a length of $6.5 \mathrm{~cm}$, were punched out to a standard ISO 37-3 shape, using a specimen cutting press from Elastocon $\mathrm{AB}$, Borås, Sweden. The specimens were tested in a climatecontrolled room at $23 \pm 1^{\circ} \mathrm{C}$ and $50 \pm 2 \% \mathrm{RH}$. A load cell 


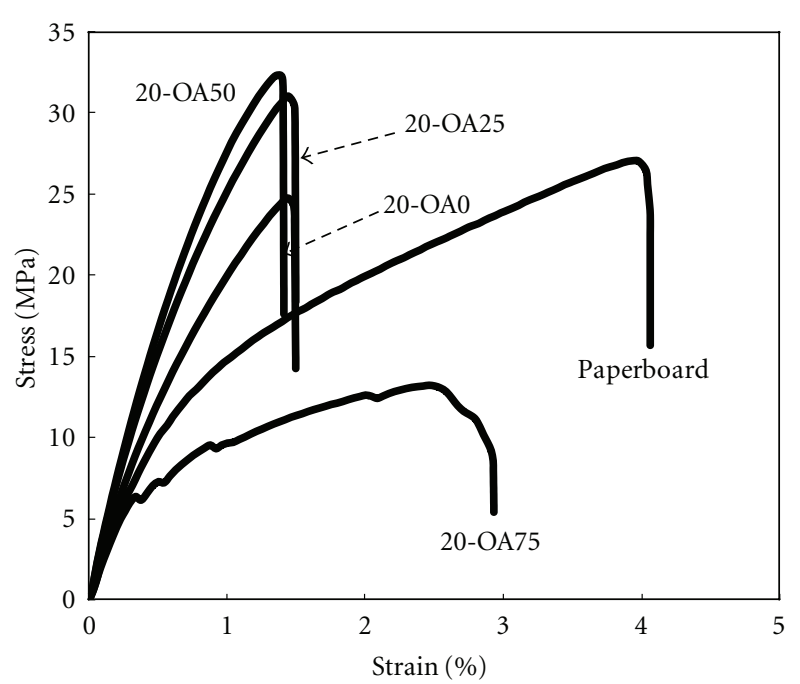

(a)

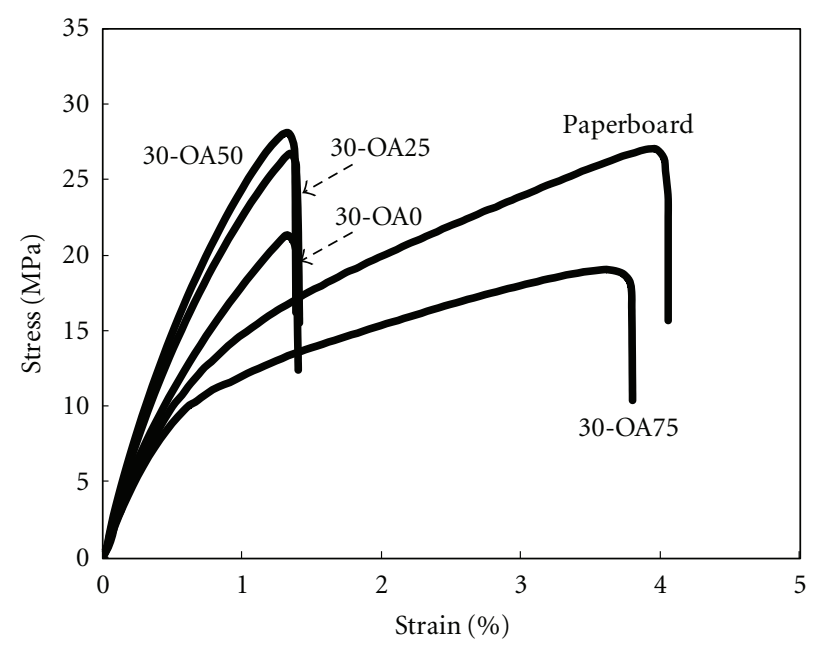

(b)

Figure 6: Stress-strain curves of the samples with (a) $20 \mathrm{wt} . \%$ and (b) $30 \mathrm{wt} . \%$ plasticizer. Note that the curves are typical examples to illustrate the trends and not the average values reported in Table 2.

of $500 \mathrm{~N}$ was used with an extension rate of $10 \mathrm{~mm} / \mathrm{min}$ and an initial grip-to-grip distance of $40 \mathrm{~mm}$. A preload of $0.1 \mathrm{~N}$ (extension rate $10 \mathrm{~mm} / \mathrm{min}$ ) was applied on the samples before measurement to ensure measurements of straight samples. The stress was obtained as the force divided by the initial cross-sectional area of the narrow section, and the strain was determined as the actual grip-to-grip distance relative to the initial grip-to-grip distance. The elastic $(E)$ modulus was estimated as the initial slope of the stress-strain curve. A sample series consisted of 10-13 specimens, which were conditioned in the climate room for $120 \mathrm{~h}$ before being tested.

2.8. Gloss Test. Gloss was measured using a Zehntner Gloss Instrument ZLR 1050-M supplied by Zehntner $\mathrm{GmbH}$ Testing Instruments, Sissach, Switzerland, at an angle of $60^{\circ}$ according to ISO 2813. Reflectance, measured at angles of $20^{\circ}$ and $60^{\circ}$ from the normal to the WG layer surface in accordance with TAPPI T480, is reported as the gloss units $G^{20}$ and $G^{60}$ ( $G U$; percentage multiple of standard). The lamp, lenses, and photodetector were spectrally corrected to give a spectral response corresponding to the CIE luminous efficiency function $(\nu(\lambda))$, which has an effective wavelength of $572 \mathrm{~nm}$. Reflection haze of the coated films was calculated according to ASTM standard method D4039. The haze index $(H)$ was defined as the difference in gloss values measured at angles of $60^{\circ}$ and $20^{\circ}\left(H=G^{60}-G^{20}\right)$ [16]. A higher $H$ value represents a higher haze.

2.9. Statistical Analysis. Statistical analyses were carried out with a statistical software program JMP version 5 (SAS Institute Inc., Cary, NC, USA). A Tukey-Kramer's HSD (honestly significant difference) test, which performs a statistical means comparison for all pairs, was used at a significance level of 0.05 .

\section{Results and Discussion}

3.1. Water Vapor Transmission Rate. It was clear that, while the paperboard had an immeasurably high sWVTR, the wheat gluten layer yielded a paperboard laminate with a finite sWVTR (Table 1). In previous work, plasticized standalone wheat gluten films also had immeasurably high sWVTR values [14]. The reason for the difference is probably that the paperboard acted as a support providing mechanical integrity and reducing moisture-induced swelling of the wheat gluten layer.

The specific water vapor transmission rate decreased with increasing amount of oleic acid in the glycerol/oleic acid mixture (Table 1). The value was 3.3 (20 wt.\% plasticizer) and 2.9 (30 wt.\% plasticizer) times lower with $75 \mathrm{wt} . \%$ oleic acid in the plasticizer mixture. This was interpreted as being due to the greater hydrophobicity of oleic acid than of glycerol [17]. In all cases, the material with $30 \mathrm{wt} . \%$ plasticizer was more permeable than the material with $20 \mathrm{wt} . \%$ plasticizer. It should be noted that the $s W V T R$ data was calculated based on the total thickness of the laminate. Significantly smaller values would be obtained if the WVTR values were instead normalized with the WG layer thickness, neglecting the paperboard, which did not contribute to the barrier properties. It should also be noted that the sWVTR values were obtained at a severe condition $(90 \% \mathrm{RH}$, $38^{\circ} \mathrm{C}$ ), which is, at least in northern Europe, not a common environment for dry food packaging.

3.2. Water Absorbency: $\operatorname{Cobb}_{60}$. The $\operatorname{Cobb}_{60}$ values for the laminated board were much higher than those of the uncoated board, but the value decreased with increasing amount of oleic acid, which was in accordance with the sWVTR data (Table 1). The low Cobb 60 value and the very high sWVTR value of the paperboard indicated that it was highly sized; water vapor was able to penetrate the pores of 


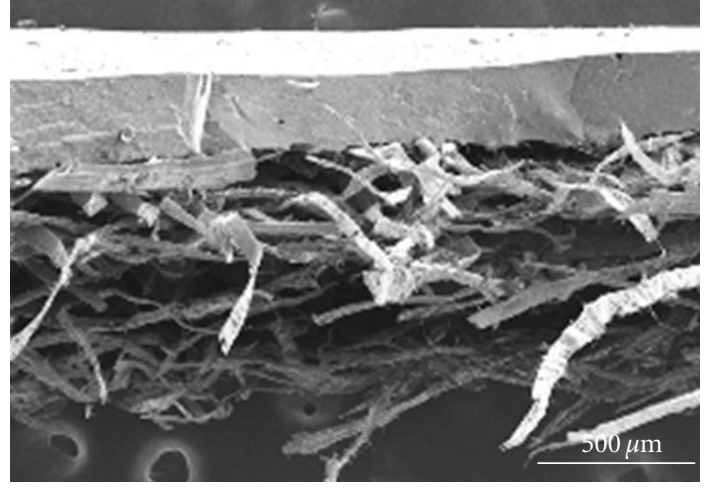

(a)

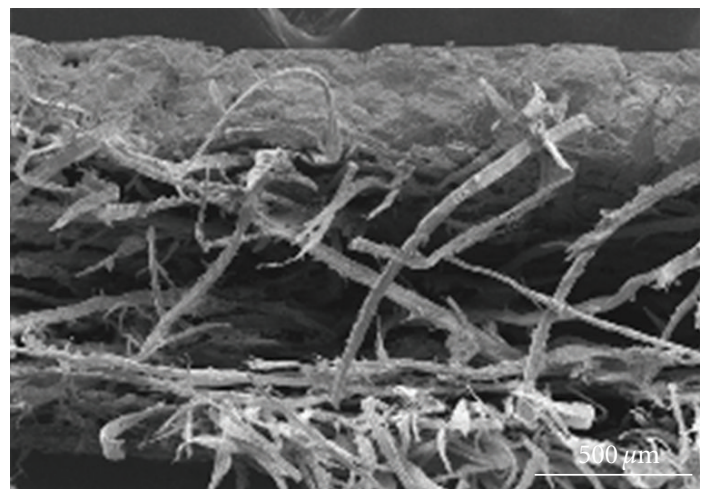

(c)

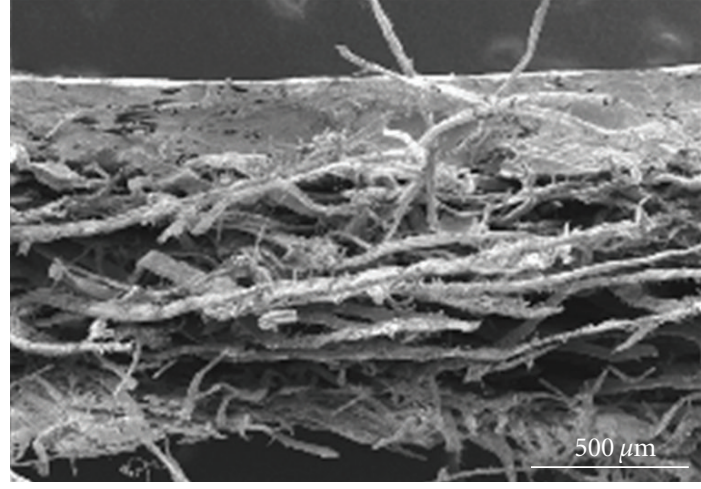

(b)

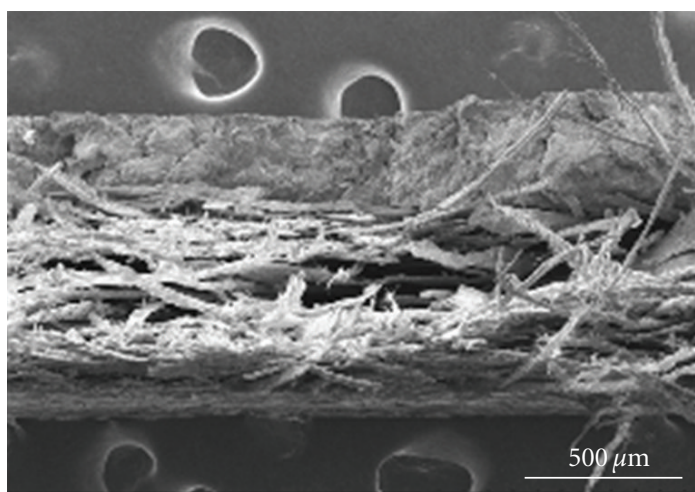

(d)

Figure 7: Cross-sections of tensile-fractured samples containing $30 \mathrm{wt} . \%$ plasticizer with (a) 0 wt.\%, (b) 25 wt.\%, (c) 50 wt.\%, and (d) 75 wt. $\%$ OA.

the board, but the absorption of liquid water was limited. The greatest difference was found for the samples with $30 \mathrm{wt} \%$ plasticizer with a decrease of ca. $24 \mathrm{~g} / \mathrm{m}^{2}$ between 0 and 75 wt. \% OA. The difference in the water absorbance between the samples with 20 and those with $30 \mathrm{wt} \% \%$ plasticizer varied with oleic acid content. With the lowest oleic acid content, the sample with $30 \mathrm{wt} . \%$ plasticizer had a significantly higher water absorption than the sample with 20 wt.\% plasticizer. As with the $s W V T R$, the effect of oleic acid on the water uptake was considered to be due to the greater hydrophobicity of the oleic acid than that of the glycerol.

3.3. Structural Characterization. The surfaces of the samples containing only glycerol felt somewhat sticky and less smooth than the surfaces of the samples containing oleic acid. The latter surfaces felt more "fat-like." Nevertheless, SEM revealed that the surface of samples with oleic acid contained cracks and a more heterogeneous structure (Figures 1 and 2). The heterogeneity increased with increasing oleic acid content and was highest for the $75 \mathrm{wt} \%$ OA samples.

Figure 3 shows that the cracks did not extend through the WG layer, which explains why the $s W V T R$ and $C_{0} b b_{60}$ values decreased with increasing oleic acid content. An exception was perhaps the sample containing $20 \mathrm{wt} . \%$ plasticizer with 75 wt.\% OA where the SEM pictures were less conclusive (Figure 3). The increased heterogeneity of this sample might explain why it had an unexpectedly high $C_{0} b b_{60}$ value (Table 1). However, if the cracks did extend through the WG layer, the $s W V T R$ and $C o b b_{60}$ values would have been significantly higher than the values obtained (Table 1). Figure 3 also indicates good bonding between the paperboard and the WG layer.

3.4. Infrared Spectroscopy. The wheat gluten protein structure was analyzed using infrared spectroscopy. The amide I absorbance between 1600 and $1700 \mathrm{~cm}^{-1}$ in Figure 4 is sensitive to changes in the protein secondary structure and reveals the state of the polymerized/aggregated structure [6]. Interestingly, all the wheat gluten layers were found to have a high degree of polymerized/aggregated structure (prominent peak at $\sim 1625 \mathrm{~cm}^{-1}$, corresponding to amide groups in intermolecular $\beta$-sheet networks [6]). The peak/shoulder at $\sim 1650 \mathrm{~cm}^{-1}$, corresponding to amide groups in disordered/alpha-helix chain conformations, was less prominent [18]. Aggregation here includes all events that "aggregate" the protein, involving both noncovalent interactions and disruption and reformation of disulfide bonds. The extent of the aggregated structure seemed to decrease with increasing oleic acid content, although the changes were small (the IR curves of the $30 \mathrm{wt} . \%$ plasticizer samples were similar to those of the $20 \mathrm{wt} \%$ plasticizer samples shown in Figure 4). Hence the $s W V T R$ and $C_{0 b} b_{60}$ 
results were most likely not due to changes in the protein structure.

Peaks associated with glycerol and oleic acid were also studied in order to verify that both components existed at the surface of the WG layer (the IR beam penetration into the sample is of the order of a few $\mu \mathrm{m}$, depending on the IR wavelength [19]). The IR showed that glycerol was indeed present at the surface, with peaks at $925 \mathrm{~cm}^{-1}$ and at $850 \mathrm{~cm}^{-1}$ assigned to the vibration of the $\mathrm{C}-\mathrm{C}$ bond and a peak at $1117 \mathrm{~cm}^{-1}$ related to the stretching of the $\mathrm{C}-\mathrm{O}$ bond (data not shown) [20]. Oleic acid was readily observed by the presence of the characteristic peak at $1710 \mathrm{~cm}^{-1}$ (attributed to the asymmetric stretching of the $\mathrm{C}=\mathrm{O}$ bond [21]). Figure 5 shows data for the $20 \mathrm{wt} . \%$ plasticizer samples. The results were similar for the $30 \mathrm{wt} . \%$ plasticizer samples. Thus both components in the plasticizer mixture were present at the surface of the WG layer to various degrees depending on the mixing ratio.

3.5. Tensile Testing. The results of the tensile tests are shown in Figure 6 and summarized in Table 2. The presence of the WG layer reduced the elongation and energy at break of the paperboard. This was probably due to that, when the WG layer fractured, the sudden increase in the load carried by the paperboard made it fracture as well. However, the difference in extensibility between the uncoated paperboard and the sample with a WG layer containing $30 \mathrm{wt} . \%$ plasticizer with 75 wt.\% OA was insignificant (Table 2). The sample with $20 \mathrm{wt} . \%$ plasticizer with $75 \mathrm{wt} . \%$ OA also had a relatively high extensibility. Both the stress at break and the modulus increased when the OA content increased from 0 to $50 \mathrm{wt} . \%$ and decreased thereafter. The strength of a few of the laminated samples and the stiffness of the $75 \mathrm{wt} . \%$ OA samples were similar to the corresponding values for the uncoated paperboard. Except for samples containing $75 \mathrm{wt} . \%$ OA, the difference in modulus, strain at break, and energy at break, between the 20 and $30 \mathrm{wt} . \%$ plasticizer samples, was insignificant. The variations in sample thicknesses could not explain the mechanical results since there were no clear trends among the samples (Table 2). Of particular interest was that the mechanical properties of the laminate did not become poorer when up to $50 \mathrm{wt} . \%$ OA was added to the glycerol plasticizer. At $75 \mathrm{wt} . \% \mathrm{OA}$, the laminates became weaker but on the other hand tougher ( $30 \mathrm{wt} . \%$ plasticizer) and more extensible. The stiffness also decreased but was still similar to that of the uncoated paperboard.

As a complement to the tensile test results, the fracture surfaces were studied with SEM (Figure 7). The paperboard exhibited a high strain to break through fiber pullout, whereas the board with a WG layer experienced a more brittle fracture. Clearly the lower strain at break of the coated paperboard was due to the gluten layer; a hypothesis is that the deformation of the paperboard was restricted by the gluten coating and that both layers were extended in parallel at the same rate, yielding smooth tensile curves. The higher strain at break for the $75 \mathrm{wt} . \%$ OA samples was probably due to poor adhesion between the paperboard and the WG layer and/or a weaker WG layer, fracturing more easily and allowing the paperboard to extend further. For the sample with $20 \mathrm{wt} . \%$ plasticizer ( $75 \mathrm{wt} . \% \mathrm{OA})$, the tensile curve showed discontinuities suggesting multiple fractures of the WG layer as the coated paperboard was deformed. This could be observed visually as crack development perpendicular to the tensile direction during the testing.

3.6. Gloss of the Laminated Paperboard. The optical appearance of the coating is often of importance. Gloss is a function of the surface refractive index, the extinction coefficient, the angle of incidence of the light beam, and the nature of the reflecting light. A surface with a gloss unit of 70 or greater at an incidence angle of $60^{\circ}$ is considered to be a high gloss surface [22]. In this respect, none of the tested sample surfaces were considered to be highly glossy (Table 3 ). Since the angle of incidence and the nature of the incident light are constant and the two plasticizer components have similar refractive indices (glycerol: 1.47 [23] and oleic acid: $1.46[24]$ at $20^{\circ} \mathrm{C}$ ), differences in the extinction coefficient and/or the absorbed light should be the main parameters responsible for the observed variations in gloss. The haze index is related to, and increases with, the irregularity and heterogeneity of the surface. Interestingly the oleic acidcontaining samples, despite the microscopic cracks, had a lower haze index than the sample containing glycerol, which is in agreement with the greater smoothness to the touch of the former samples (Table 3 ).

\section{Conclusions}

It is known that wheat gluten is a very good oxygen barrier under low-moisture conditions and with a small amount of plasticizer [14]. The results here show the potential of limiting also the water uptake and water vapor transmission rate by incorporating a more hydrophobic component into the hydrophilic plasticizer. This opens up for an interesting concept to create a fully renewable protein-based multilayer water and oxygen barrier WG layer on the outside of paperboard for dry foods. The outer water vapor barrier layer should have a more hydrophobic component (e.g., oleic acid) in the plasticizer (e.g., glycerol), whereas the inner oxygen barrier layer should contain only a small amount of the hydrophilic plasticizer. This concept would probably work not only for wheat gluten but also for other filmforming proteins such as zein and soy protein. Finally, it is important here to note that the laminate is not a "coated" paperboard in that we are here using thicker protein layers. It should rather be considered as a protein/paperboard laminate packaging concept where each layer contributes with important properties to the total, as well as to the adjacent, layer.

\section{Acknowledgments}

Vinnova, the Swedish Governmental Agency for Innovation Systems, and the "RenewFuncBarr" consortium are thanked for financial support. 


\section{References}

[1] B. Lagrain, B. Goderis, K. Brijs, and J. A. Delcour, "Molecular basis of processing wheat gluten toward biobased materials," Biomacromolecules, vol. 11, no. 3, pp. 533-541, 2010.

[2] T. O. J. Blomfeldt, R. T. Olsson, M. Menon, D. Plackett, E. Johansson, and M. S. Hedenqvist, "Novel foams based on freeze-dried renewable vital wheat gluten," Macromolecular Materials and Engineering, vol. 295, no. 9, pp. 796-801, 2010.

[3] I. Olabarrieta, S. W. Cho, M. Gällstedt, J. R. Sarasua, E. Johansson, and M. S. Hedenqvist, "Aging properties of films of plasticized vital wheat gluten cast from acidic and basic solutions," Biomacromolecules, vol. 7, no. 5, pp. 1657-1664, 2006.

[4] M. Gällstedt, A. Mattozzi, E. Johansson, and M. S. Hedenqvist, "Transport and tensile properties of compression-molded wheat gluten films," Biomacromolecules, vol. 5, no. 5, pp. 2020 2028, 2004.

[5] N. H. Ullsten, M. Gällstedt, E. Johansson, A. Gräslund, and M. S. Hedenqvist, "Enlarged processing window of plasticized wheat gluten using salicylic acid," Biomacromolecules, vol. 7, no. 3, pp. 771-776, 2006.

[6] S. W. Cho, M. Gällstedt, E. Johansson, and M. S. Hedenqvist, "Injection-molded nanocomposites and materials based on wheat gluten," International Journal of Biological Macromolecules, vol. 48, no. 1, pp. 146-152, 2011.

[7] N. H. Ullsten, S. W. Cho, G. Spencer, M. Gällstedt, E. Johansson, and M. S. Hedenqvist, "Properties of extruded vital wheat gluten sheets with sodium hydroxide and salicylic acid," Biomacromolecules, vol. 10, no. 3, pp. 479-488, 2009.

[8] J. Han, S. Salmieri, C. Le Tien, and M. Lacroix, "Improvement of water barrier property of paperboard by coating application with biodegradable polymers," Journal of Agricultural and Food Chemistry, vol. 58, no. 5, pp. 3125-3131, 2010.

[9] B. Ş. Kayserilioğlu, U. Bakir, L. Yilmaz, and N. Akkaş, "Drying temperature and relative humidity effects on wheat gluten film properties," Journal of Agricultural and Food Chemistry, vol. 51, no. 4, pp. 964-968, 2003.

[10] M. Vargas, A. Albors, A. Chiralt, and C. González-Martínez, "Characterization of chitosan-oleic acid composite films," Food Hydrocolloids, vol. 23, no. 2, pp. 536-547, 2009.

[11] L. Fernández, E. D. De Apodaca, M. Cebrián, M. C. Villarán, and J. I. Maté, "Effect of the unsaturation degree and concentration of fatty acids on the properties of WPI-based edible films," European Food Research and Technology, vol. 224, no. 4, pp. 415-420, 2007.

[12] N. Gontard, S. Marchesseau, J.-I. Cuq, and S. Guilbert, "Water vapour permeability of edible bilayer films of wheat gluten and lipids," International Journal of Food Science and Technology, vol. 30, no. 1, pp. 49-56, 1995.

[13] N. Gontard, C. Duchez, J.-I. Cuq, and S. Guilbert, "Edible composite films of wheat gluten and lipids: water vapour permeability and other physical properties," International Journal of Food Science and Technology, vol. 29, no. 1, pp. 3950, 1994.

[14] S. W. Cho, M. Gällstedt, and M. S. Hedenqvist, "Properties of wheat gluten/poly(lactic acid) laminates," Journal of Agricultural and Food Chemistry, vol. 58, no. 12, pp. 7344-7350, 2010.

[15] M. Gällstedt, J. Törnqvist, and M. S. Hedenqvist, "Properties of nitrocellulose-coated and polyethylene-laminated chitosan and whey films," Journal of Polymer Science, Part B, vol. 39, no. 10, pp. 985-992, 2001.
[16] S. I. Hong and J. M. Krochta, "Whey protein isolate coating on LDPE film as a novel oxygen barrier in the composite structure," Packaging Technology and Science, vol. 17, no. 1, pp. 13-21, 2004.

[17] C. M. Hansen, Hansen Solubility Parameters: A User's Handbook, CRC Press, Boca Raton, Fla, USA, 2000.

[18] T. O. J. Blomfeldt, R. Kuktaite, E. Johansson, and M. S. Hedenqvist, "Mechanical properties and network structure of wheat gluten foams," Biomacromolecules, vol. 12, no. 5, pp. 1707-1715, 2011.

[19] M. S. Hedenqvist, M. Krook, and U. W. Gedde, "Two-stage sorption in rubbery semicrystalline polymers: transport of primary alcohols in polyesteramide," Polymer, vol. 43, no. 10, pp. 3061-3068, 2002.

[20] P. Guerrero, A. Retegi, N. Gabilondo, and K. De La Caba, "Mechanical and thermal properties of soy protein films processed by casting and compression," Journal of Food Engineering, vol. 100, no. 1, pp. 145-151, 2010.

[21] L. Zhang, R. He, and H. C. Gu, "Oleic acid coating on the monodisperse magnetite nanoparticles," Applied Surface Science, vol. 253, no. 5, pp. 2611-2617, 2006.

[22] J. W. Lee, S. M. Son, and S. I. Hong, "Characterization of protein-coated polypropylene films as a novel composite structure for active food packaging application," Journal of Food Engineering, vol. 86, no. 4, pp. 484-493, 2008.

[23] L. F. Hoyt, "New table of the refractive index of pure glycerol at $20^{\circ} \mathrm{C}$," Industrial \& Engineering Chemistry Research, vol. 26, no. 3, pp. 329-332, 1934.

[24] F. F. De Sousa, S. G. C. Moreira, S. J. D. S. Da Silva, J. Del Nero, and P. Alcantara, "Dielectric properties of oleic acid in liquid phase," Journal of Bionanoscience, vol. 3, no. 2, pp. 139-142, 2009. 

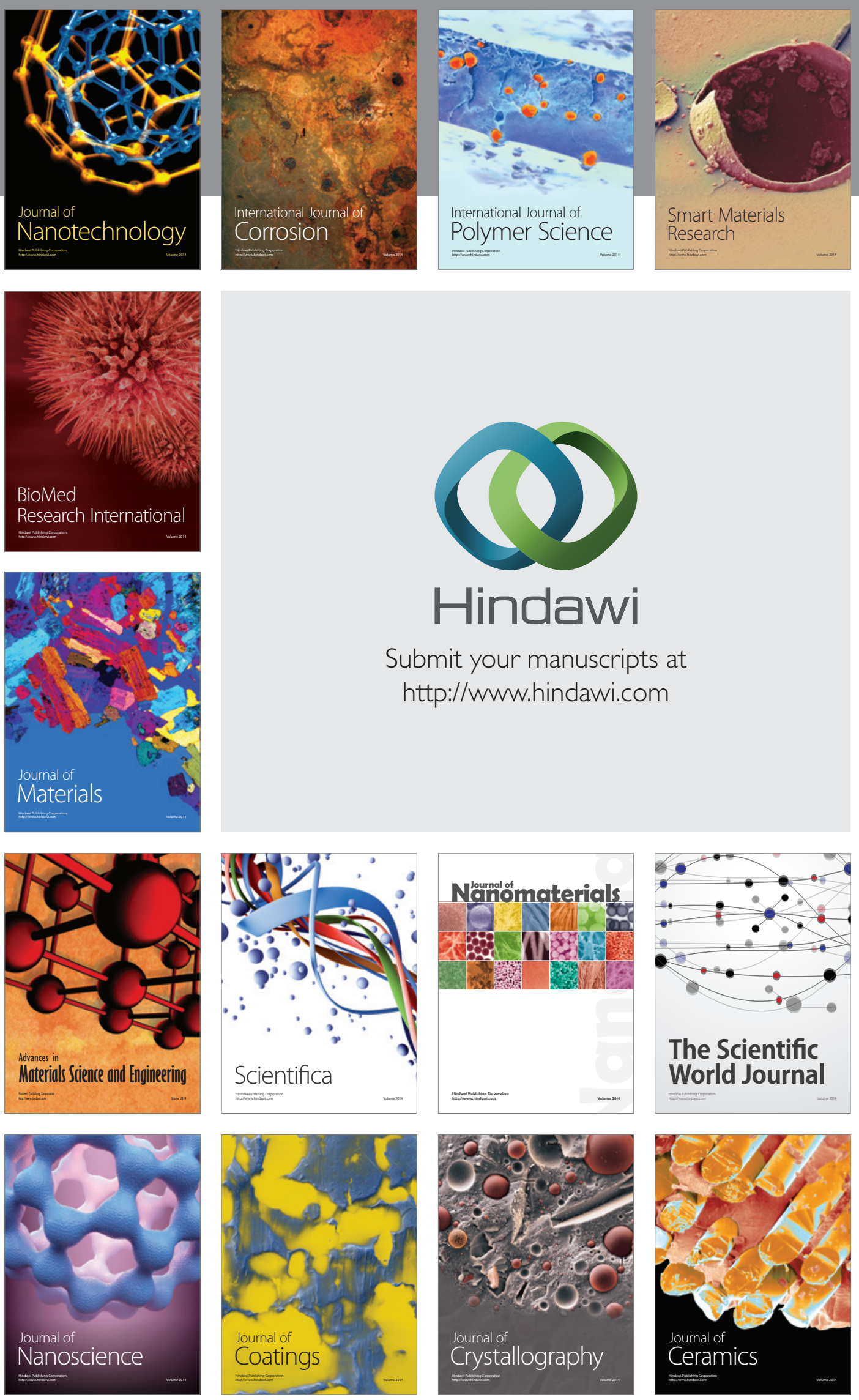

The Scientific World Journal

Submit your manuscripts at

http://www.hindawi.com

\section{World Journal}

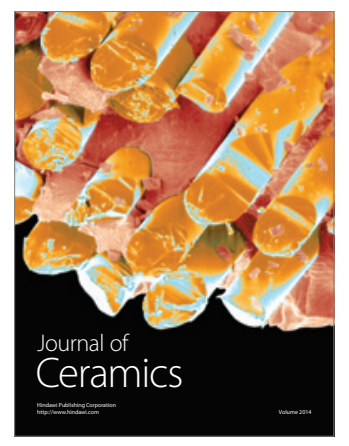

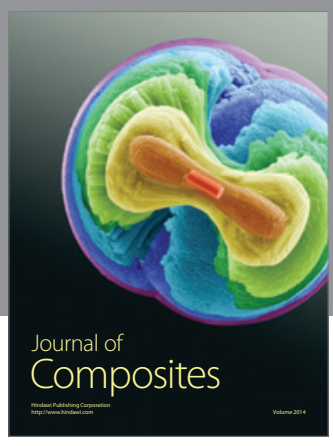
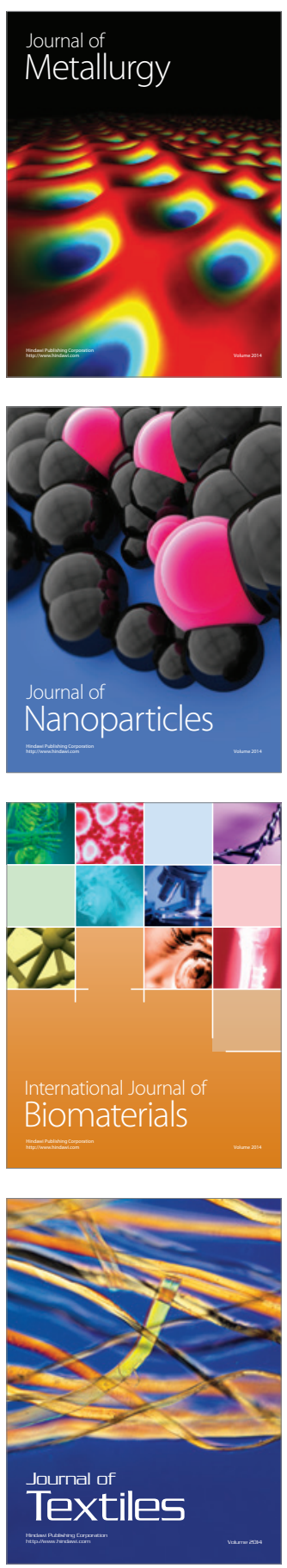